\title{
Treatment Effect of Mammary Duct Exploration Combined with Focal Resection on Granulomatous Lobular Mastitis
}

\author{
Ximeng Zuo \\ Xiaoguang Shi \\ Xiang Gao \\ Rui Lai \\ Pengzhou Liu \\ Ze Zhao
}

Department of General Surgery, Dongzhimen Hospital, Beijing University of Chinese Medicine, Beijing, 100700 , People's Republic of China
Correspondence: Xiaoguang Shi Department of General Surgery, Dongzhimen Hospital, Beijing University of Chinese Medicine, Beijing, 100700,

People's Republic of China

$\mathrm{Tel} / \mathrm{Fax}+8613301119560$

Email shixiaoguang221@163.com
Objective: This study aims to summarize the treatment of granulomatous lobular mastitis with a low recurrence rate and high satisfaction rate.

Methods: In this study, the epidemiology and treatment effect was analyzed based on the general data and treatment effects. Patients treated for granulomatous lobular mastitis at the Dongzhimen Hospital, Beijing University of Chinese Medicine, and Beijing Contemporary Hospital from October 24, 2016, to May 8, 2019, were selected as subjects for the study.

Results: The results revealed that the common features of granulomatous lobular mastitis were nipple retraction, history of induced abortion, nipple discharge, history of thyroid disease, history of lactation mastitis, and mental illness. The cure rate of the disease was $100 \%$, the recurrence rate was $0.38 \%$, and the patient satisfaction rate was $97.71 \%$.

Conclusion: The combination of mammary duct exploration and focal resection has a positive effect on the treatment of this disease and is worthy of clinical popularization.

Keywords: breast duct exploration, granulomatous lobular mastitis, surgical treatment, retrospective study, prolactin

\section{Introduction}

Granulomatous lobular mastitis (GLM) was first discovered by Kessler et al in 1972. ${ }^{1,2}$ At present, there is no unified standard for the treatment of GLM at home or abroad. Its treatment methods can be classified as antibiotic therapy, antituberculosis therapy, glucocorticoid therapy, immunosuppressant therapy, and incision and drainage. However, these therapies have differing degrees of problems, such as poor treatment outcomes and disease recurrence. At present, surgical resection has been used. However, there is still a series of issues, such as the risk of recurrence and the impact on the appearance of the breast. ${ }^{3-6}$ Conservative treatment using traditional Chinese medicine (TCM) primarily involves methods of incision, drainage, and debridement, combined with external applications, dressing changes, and the oral administration of TCM drugs, even if the effects of these methods on the breast appearance are milder than traditional surgery. The course of the disease usually ranges from 3 to 12 months. Changing the dressing is generally very painful, and the possibility of a recurrence exists (the recurrence rate is usually $20-30 \%)^{7}$

Compared with conservative treatments, the method of local resection of the lesion combined with the exploration of the mammary duct used in this study can reduce the resected lesions and ensure breast appearance. It can also reduce 
patients' pain, achieving the purpose of the treatment with a low recurrence rate. Therefore, the present study was a retrospective study summarizing GLM treatment.

\section{Materials and Methods}

\section{Patients}

Patients diagnosed with GLM through histopathology and hospitalized at Dongzhimen Hospital, Beijing University of Chinese Medicine, and other local Beijing hospitals from October 24, 2016, to May 8, 2019, were enrolled in this study. GLM was defined as "perilobular granulomatous inflammation, accompanied by predominant infiltration of neutrophils with or without intralobular microabscess formation" in the present retrospective cohort study.

\section{Inclusion and Exclusion Criteria}

Inclusion criteria: (1) patients positively diagnosed with GLM; (2) patients with complete medical data; (3) patients older than 18 years.

Exclusion criteria: (1) patients with unclear pathology and an incomplete medical history; (2) patients with nonlactation specific mastitis, such as tuberculosis granulomatous mastitis; (3) patients who terminated treatment during hospitalization and were discharged spontaneously. ${ }^{8}$

\section{Treatment Regimen}

The patients with apparent dark areas indicated by color Doppler ultrasound before the operation underwent incision and drainage, while the other patients were operated on directly.

\section{Incision and Drainage}

Routine disinfection was performed, and surgical drapes were placed. After successful local anesthesia induction, the incision was made from the puncture point to the gland layer. The pus chamber was separated bluntly, and the residual cavity was rinsed repeatedly with normal saline, covered with sterile oil gauze, wet dressed with $10 \% \mathrm{NaCl}$ solution, then bandaged with compression and elastic bandages. There were daily dressing changes until there was no noticeable purulent exudation; then surgery was performed. ${ }^{9}$ Preoperative ancillary examinations included breast ultrasound and enhanced breast magnetic resonance imaging in determining the scope and focus of the lesion.

Surrounding healthy tissue was transferred to fill the defect. When a large portion of the breast has been removed, the lateral chest wall fat fascia flap can be appropriately dissociated. When the flap is free, protecting the blood supply of the pedicle should be observed. There should be enough length left in the pedicle of the tissue flap to ensure that the tension is moderate when the flap is shifted and flipped. The tissue flap was transferred to the breast defect, and it was repaired appropriately. The tissue flap was sutured and fixed with the surrounding tissue, and a drainage tube was placed in the wound cavity.

\section{Surgical Treatment}

The method of extended resection of the lesion combined with an exploration of the mammary duct was adopted before the operation. The relevant auxiliary examinations were performed to define the lesion areas and scope. The primary surgery process is as follows (Figure 1): (1) removing all the breast lesions; (2) removing lactiferous ducts that had a relationship to the lesion; (3) reconstruction of the breast by transposition with the residual glands and the surrounding tissues, trying to maintain a good breast shape. ${ }^{10}$ The granuloma of lobular mastitis is usually different from normal breast tissue and is dull white to dull yellow fleshy tissue with inadequate blood supply. After the necrotic granulation tissue resection, the breast tissue was radially dissected with the nipple and areola as the center. The large ducts and lobules of the remaining breast tissue in the four quadrants were examined sequentially, and the cheesy yellow fluid and tiny abscesses in the breast ducts were removed.

\section{Medication Therapy}

Xihuang capsules (Chinese traditional medicine; $1.2 \mathrm{~g}$, twice a day) and intravenous antibiotics were used for GLM patients. For some patients, glucocorticoids, such as methylprednisolone tablets, were added.

\section{Observation Indexes}

In this study, the main observation indexes included age, gender, past medical history, reproductive history, medication history, physical examination, auxiliary examination, treatment plan, and clinical effect. The evaluation standard of the clinical effect of acne-type mastitis in China was adopted. The details are as follows. Cure: a clinical cure is achieved, and no recurrence is observed for half a year, or a clinical cure is achieved, and no residual lesions are detected by ultrasound. Clinical cure: the systemic symptoms disappear, the primary inflammatory lesions are clinically nonpalpable, and the wound or fistula heals. No cure: the primary inflammatory lesions remain clinically palpable, and there is no significant improvement or aggravation of systemic symptoms. The 
A

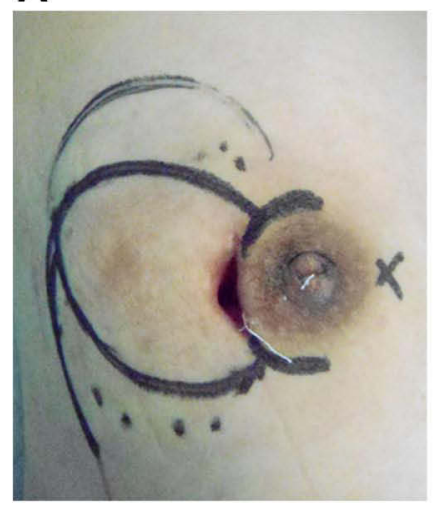

D

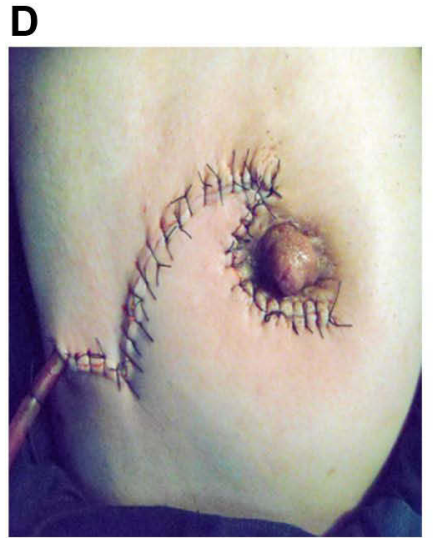

B

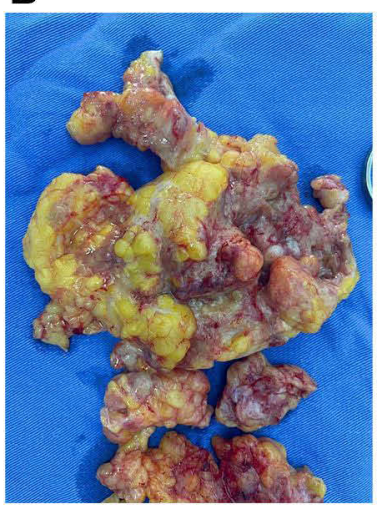

E
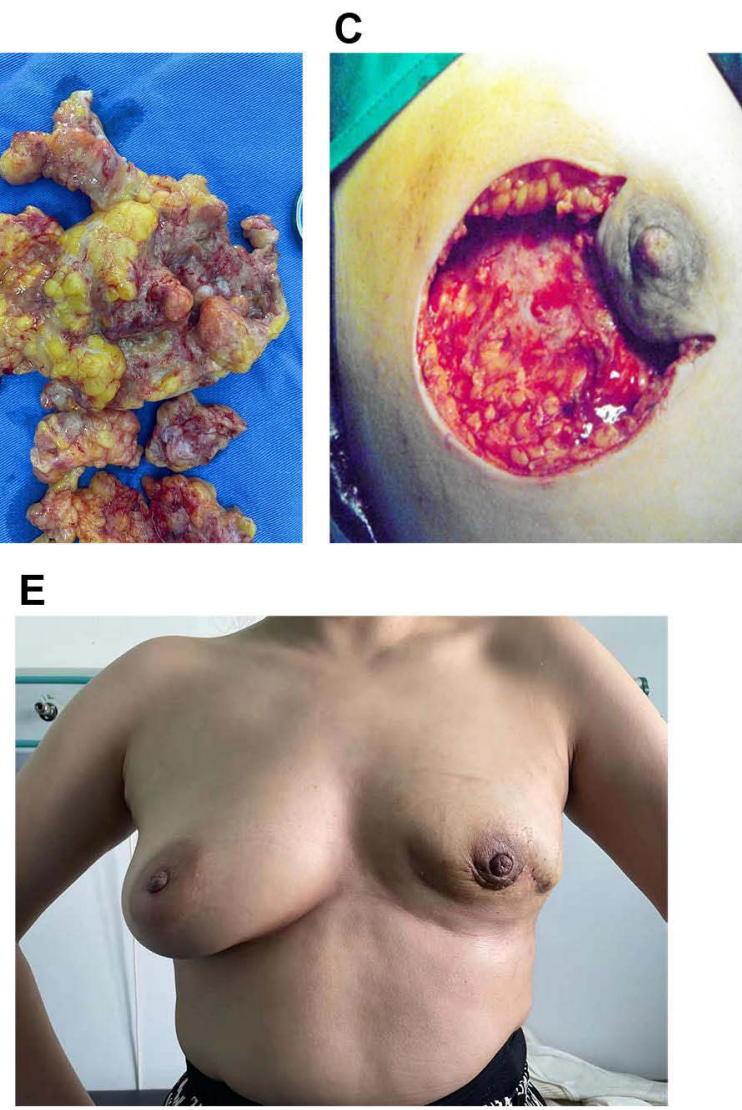

Figure I Pictures of the surgery and healing.

Notes: (A) Incision selection. (B) Gross specimen. (C) After probing. (D) Suture and drainage tube. (E) One month after surgery.

patient satisfaction rate was divided into five levels: very satisfied, satisfied, neutral, dissatisfied, and very dissatisfied.

\section{Statistical Analysis}

The statistical software SPSS 21.0 was used to analyze the data. Measurement data were expressed as mean \pm standard deviation (SD). Count data were expressed as a percentage (\%).

\section{Results}

\section{General Data}

A total of 1309 GLM patients were enrolled in this study (another 18 patients were withdrawn). All participants were female. Their ages ranged from 18-53 years old. Among these, 52 patients had no childbirth in their reproductive history, 828 patients had given birth to one child, and 429 patients had given birth to two children. In terms of disease history, nine patients had hypertension, 20 had diabetes mellitus, 58 had thyroid disease, 26 had a uterine or ovarian disease, 39 had a history of mastitis in lactation, 12 had a mental illness, and one patient had a malignant breast tumor. The duration of lactation history was $0-53$ months. The general data of the 1309 patients are shown in Table 1.

The most significant characteristic of GLM is perilobular granulomatous inflammation (Figure 2). The most commonly observed intralobular inflammatory cells were neutrophils, followed by lymphocytes. In some cases, foam cells could be found in or around the duct wall.

\section{Previous Medication and Physical Examination Data Previous Medication}

Of the 1309 patients, 370 were not treated with any drug, and the other 939 were treated with different degrees of patented Chinese and Western medicine, but the symptoms were not relieved. The main drugs were hormones, antibiotics, and antituberculosis drugs.

\section{Adjuvant Examination}

Of the 1309 patients, the average leukocyte count was $7.98 \times 10^{9} / \mathrm{L}$, and the average value of C-reactive protein (CRP) was 7.77. The prolactin levels were normal in 916 
Table I The Clinical Characteristics of I 309 GLM Patients

\begin{tabular}{|c|c|}
\hline Characteristics & Results \\
\hline Age, mean (range), years & $31.33 \pm 5.06(18-53)$ \\
\hline Weight, mean (range), kg & $67.82 \pm 15.40(55-140)$ \\
\hline \multicolumn{2}{|l|}{ Highest education level, n (\%) } \\
\hline High school or less & $687(52.48)$ \\
\hline Junior college & $300(22.92)$ \\
\hline Bachelor's degree & $262(20.02)$ \\
\hline Graduate degree & $60(4.58)$ \\
\hline Pregnancy history, n (\%) & $1257(96.28)$ \\
\hline Frequency of pregnancy, n (range) & $1.28(0-3)$ \\
\hline Delivery, n (\%) & $783(59.82)$ \\
\hline Abortion history, n (\%) & $617(47.14)$ \\
\hline \multicolumn{2}{|l|}{ Insurance status, $\mathrm{n}(\%)$} \\
\hline Insured & $220(16.81)$ \\
\hline Uninsured & $1089(83.19)$ \\
\hline Lactation, n (\%) & $871(66.54)$ \\
\hline \multicolumn{2}{|l|}{ Location, n (\%) } \\
\hline Around areola & $62(4.74)$ \\
\hline Peripheral part & $1247(95.26)$ \\
\hline \multicolumn{2}{|l|}{ Side, n (\%) } \\
\hline Left & $622(47.5 \mathrm{I})$ \\
\hline Right & $568(43.39)$ \\
\hline Bilateral & $119(9.10)$ \\
\hline Nipple Retraction, n (\%) & $506(38.66)$ \\
\hline Galactorrhea, n (\%) & $67(5.12)$ \\
\hline Abscess/ulceration, n (\%) & $577(44.10)$ \\
\hline Diameter of mass, mean (range), $\mathrm{cm}$ & $9.18 \pm 3.568(1-26)$ \\
\hline \multicolumn{2}{|l|}{ Medical history, n (\%) } \\
\hline Hypertension & $9(0.69)$ \\
\hline Diabetes mellitus & $20(1.53)$ \\
\hline Thyroid disease & $58(4.43)$ \\
\hline Uterine or ovarian disease & $26(1.99)$ \\
\hline Mastitis in lactation & $39(2.98)$ \\
\hline Mental illness & $12(0.92)$ \\
\hline Malignant tumor of the breast & I $(0.08)$ \\
\hline
\end{tabular}

patients, increased in 352 patients, decreased in four patients, and testing was not done in 61 patients. Ultrasonography revealed irregular hypoechoic or mixed echogenicity, and dark liquid areas and sinuses could be seen in the lower portion in 1334 patients. Of these masses, the maximum transverse diameter was $26 \mathrm{~cm}$, the average value was $9.28 \mathrm{~cm}$, the maximum length was
$27 \mathrm{~cm}$, and the average value was $12.51 \mathrm{~cm}$. Duct expansion could be seen in 277 patients. All 1309 patients had GLM, and three had intraductal breast malignancy.

\section{Clinical Effect}

It often took 7-10 days for patients to achieve healing after the surgical intervention. All of the patients were cured $(100 \%)$, and at one year follow-up, five patients experienced a recurrence (3.8\%), and 101 patients had a contralateral recurrence $(7.7 \%)$.

\section{Patient Satisfaction Rate}

Among the patients, 1279 (97.71\%) were very satisfied with the treatment outcome.

\section{Feature Analysis}

Analysis of the data of this study revealed that the high incidence population of GLM is 28-35-year-old women. However, there are rare individual onsets in men. ${ }^{11-13}$ Nipple retraction, history of induced abortion, nipple discharge, history of thyroid disease, history of lactation mastitis, and history of mental illness were the common factors of GLM. There is a certain chance of an occurrence on the opposite side in patients with GLM who had unilateral incidents, even if the ipsilateral side was completely cured. ${ }^{14}$

\section{Discussion}

At present, the incidence of GLM globally is sporadic. Most of the cases reported abroad come from the Mediterranean countries, the Middle East, the United States, the United Kingdom, France, and other European and North American countries. A study reported that all provinces in mainland China studied the disease except for Qinghai and Tibet. However, the disease study is restricted by the levels of economy and culture. ${ }^{15-17}$

At present, there are a variety of pathogenesis theories for GLM, such as bacterial infection, changes in patients' autoimmune function, and hormone levels. ${ }^{14}$ Xiaoguang Shi, the general surgery director of Dongzhimen Hospital, considers that the leading cause of this disease is type IV allergy, or delayed allergy, induced under special conditions (such as changes in hormone and prolactin levels) that accumulates in the breast ducts as residual milk after lactation or the secretions that cannot be eliminated due to duct expansion and duct lesions. Therefore, the main treatment points for GLM are (1) glucocorticoids used to inhibit the type 
A

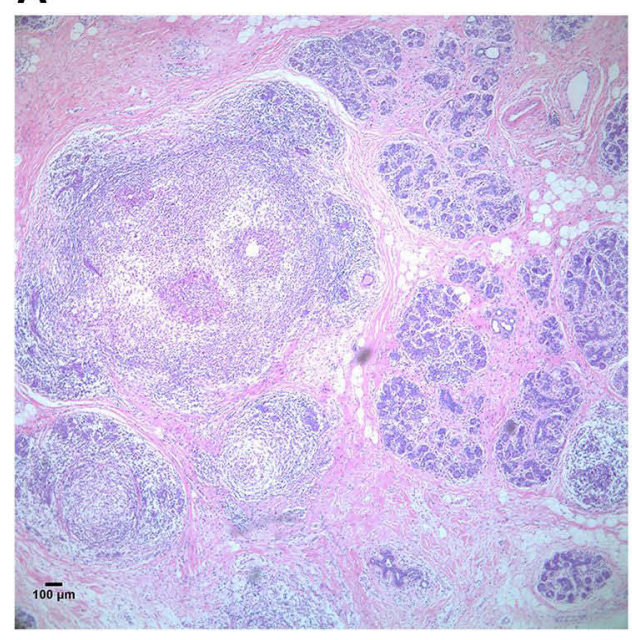

B

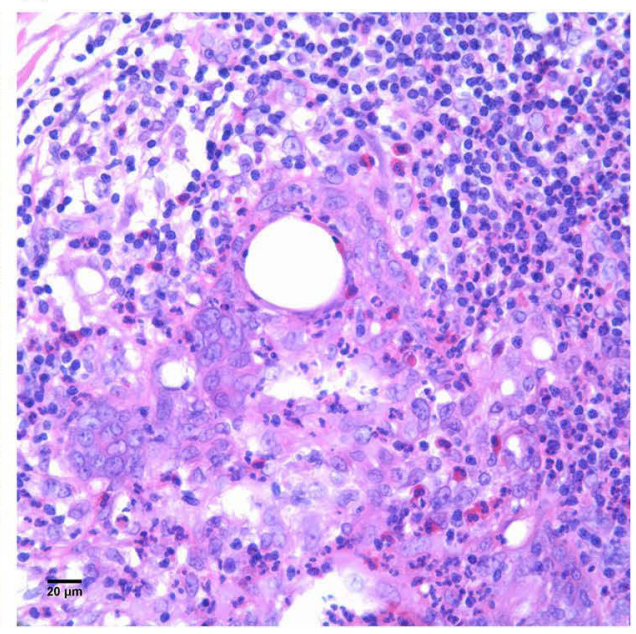

Figure 2 Typical histopathological features of granulomatous lobular mastitis. Note: (A) 40X. (B) 400X

IV allergy caused by an immune response, (2) surgical treatment to remove the lesions; mammary duct exploration is performed to remove the diseased ducts and the accumulation in the ducts to root out the cause of the reaction, (3) traditional Chinese medicine used to regulate the state of the whole body to thoroughly prevent a recurrence, and (4) close observation, reassurance, and patient education are the favored management for GLM. ${ }^{3}$

In addition, before the operation, the abscess should be cut open and drained adequately according to the patient's condition to reduce the scope of inflammatory lesions, which can significantly reduce the scope of the radical operation and maintain the breast appearance.

At present, the treatment method supported by this theory has achieved high-quality effects in clinical practice. It can effectively reduce the recurrence rate, but its pathophysiology remains to be discussed.

The advantage of this retrospective study is a larger sample size. This study has a good representation considering the low incidence of the disease. The limitations are that most of the case records about lactation history were absent. In addition, due to the differing levels of the resident doctors, there may be an information bias in the physical examination records; the data lacked aestheticrelated scores. The evaluation of aesthetic-related effects of these surgical procedures remains to be determined. In the future, more complicated statistical methods should be used to analyze data.

\section{Conclusion}

Lesion resection combined with mammary duct exploration has satisfactory effects in the treatment of GLM and is worthy of popularization and application in clinical diagnosis and treatment. The reduction of lesions with debridement and drainage before the operation followed by the radical operation has evident assistive effects in the treatment of GLM, which can make the procedure more effective.

\section{Data Sharing Statement}

We declared that materials described in the manuscript, including all relevant raw data, will be freely available to any scientist wishing to use them for non-commercial purposes, without breaching participant confidentiality.

\section{Ethics Approval and Consent to Participate}

I confirm that I have read the Editorial Policy pages. This study was conducted with approval from the Ethics Committee of Dongzhimen Hospital, Beijing University of Chinese Medicine. This study was conducted in accordance with the declaration of Helsinki. All patients provided written informed consent prior to enrollment in the study. All participants signed a document of informed consent for publication.

\section{Acknowledgments}

We are particularly grateful to all the people who have given us help on our article. 


\section{Funding}

Young teachers program of Beijing University of Chinese Medicine. Project No.: 2017-JYB-JS-063.

\section{Disclosure}

None of the authors have any financial disclosure or conflicts of interest in this work.

\section{References}

1. Kessler E, Wolloch Y. Granulomatous mastitis: alesion clinically simulating carcinoma. Am J Clin Pathol. 1972;58(6):642-646. doi:10.1093/ajcp/58.6.642

2. Zhou F, Yu LX, Ma ZB, et al. Granulomatous lobular mastitis. Chronic Dis Transl Med. 2016;2(1):17-21. doi:10.1016/j.cdtm.2016.02.004

3. Davis J, Cocco D, Matz S, et al. Komenaka. Re-evaluating if observation continues to be the best management of idiopathic granulomatous mastitis. Surgery. 2019;7:pii: S0039-6060(19)30420-9.

4. Kim J, Tymms KE, Buckingham JM. Methotrexate in the management of granulomatous mastitis. ANZ J Surg. 2003;73(4):247-249. doi:10.1046/j.1445-1433.2002.02564.x

5. Lei X, Chen K, Zhu L, et al. Treatments for idiopathic granulomatous mastitis: systematic review and meta-analysis. Breastfeed Med. 2017;12(7):415-421. doi:10.1089/bfm.2017.0030

6. Bouton ME, Jayaram L, O'Neill PJ, Hsu CH, Komenaka IK. Management of idiopathic granulomatous mastitis with observation. Am J Surg. 2015;210(2):258-262. doi:10.1016/j.amjsurg.2014.08.044

7. Li J. Diagnosis and treatment of 75 patients with idiopathic lobular granulomatous mastitis. J Invest Surg. 2019;32(5):414-420. doi:10.1080/08941939.2018.1424270
8. Brownson KE, Bertoni DM, Lannin DR, et al. Granulomatous lobular mastitis- another paradigm shift in treatment. Breast J. 2019;25 (4):790-791. doi:10.1111/tbj.13338

9. Chen L, Zhang XY, Wang YW, et al. Granulomatous lobular mastitis: a clinicopathological analysis of 300 cases. Zhonghua Bing Li Xue Za Zhi. 2019;48(3):231-236. doi:10.3760/cma.j.issn.0529-5807.201 9.03.012

10. Shin YD, Park SS, Song YJ, et al. Is surgical excision necessary for the treatment of granulomatous lobular mastitis? BMC Womens Health. 2017;17(1):49. doi:10.1186/s12905-017-0412-0

11. Korkut E, Akcay MN, Karadeniz E, et al. Granulomatous mastitis: a Ten-year experience at a University Hospital. Eurasian $J$ Med. 2015;47(3):165-173. doi:10.5152/eurasianjmed.2015.118

12. Mahlab-Guri K, Asher I, Allweis T, et al. Granulomatous lobular mastitis. Isr Med Assoc J. 2015;17(8):476-480.

13. Gautier N, Lalonde L, Tran-Thanh D, et al. Chronic granulomatous mastitis: imaging, pathology and management. Eur $J$ Radiol. 2013;82:e165-e175. doi:10.1016/j.ejrad.2012.11.010

14. Altintoprak F, Kivilcim T, Ozkan OV. Aetiology of idiopathic granulomatous mastitis. World J Clin Cases. 2014;2(12):852-858. doi:10.12998/wjcc.v2.i12.852

15. Sellitto A, Santoriello A, De Fanis U, et al. Granulomatous lobular mastitis: another manifestation of systemic lupus erythematosus? Breast J. 2013;19(3):331-332. doi:10.1111/tbj.12111

16. Hur SM, Cho DH, Lee SK, et al. Experience of treatment of patients with granulomatous lobularmastitis. J Korean Surg Soc. 2013;85 (1):1-6. doi:10.4174/jkss.2013.85.1.1

17. Calero-Paniagua I, Coca-Gonzáles CP, Amao-Ruiz EJ, et al. Idiopathic granulomatous lobular mastitis: a case report. Med Clin (Barc). 2014;142(5):229-230. doi:10.1016/j.medcli.2013.05.038
Journal of Inflammation Research

\section{Publish your work in this journal}

The Journal of Inflammation Research is an international, peerreviewed open-access journal that welcomes laboratory and clinical findings on the molecular basis, cell biology and pharmacology of inflammation including original research, reviews, symposium reports, hypothesis formation and commentaries on: acute/chronic inflammation; mediators of inflammation; cellular processes; molecular

\section{Dovepress}

mechanisms; pharmacology and novel anti-inflammatory drugs; clinical conditions involving inflammation. The manuscript management system is completely online and includes a very quick and fair peerreview system. Visit http://www.dovepress.com/testimonials.php to read real quotes from published authors. 